\title{
Visible-Light Mediated Carbamoyl Radical Addition to Heteroarenes
}

\author{
Ashique Hussain Jatoi, Govind Goroba Pawar, Frédéric Robert, and Yannick Landais*
}

The generation of carbamoyl radicals, followed by their addition to heteroarenes was performed under mild conditions through a metal-free photocatalyzed oxidative decarboxylation of oxamic acids. The process has been applied to the carbamoylation of heteroaromatic bases using ?-aminoacid-derived oxamic acids leading to the corresponding amides without racemization.

Carbamoyl radicals constitute a useful class of reactive intermediates, exhibiting a relatively long lifetime as compared to that of their acyl analogues, which tend to decarbonylate easily to generate alkyl radicals. ${ }^{1}$ Although these radical species have attracted less interest than acyl radicals, they were shown to efficiently add, both inter- and intramolecularly, to unsaturated systems, including alkenes and alkynes, ${ }^{2}$ arenes ${ }^{3}$ and heteroarenes. ${ }^{4}$ Loss of hydrogen under oxidative conditions also allow their conversion into useful isocyanates. ${ }^{5}$ Carbamoyl radicals are accessible through essentially three main routes: (1) the $\mathrm{C}-\mathrm{X}$ bond cleavage in $\mathrm{R}_{2} \mathrm{~N}(\mathrm{C}=\mathrm{O}) \mathrm{X}$ precursors $\left(\mathrm{X}=\mathrm{H}^{4,6}\right.$ xanthate, ${ }^{7} \mathrm{SPh},{ }^{8} \mathrm{Co}(\mathrm{salen}){ }^{9}$..), (2) the photoredox reductive decarboxylation of $\mathrm{N}$-hydroxyphthalimido oxamides ${ }^{3}$ and (3) the oxidative decarboxylation of oxamic acids. ${ }^{5,10}$ These acids are readily available by combination of amines and oxalic acid derivatives ${ }^{11}$ and constitute potent precursors of carbamoyl radicals. The generation of carbamoyl radicals from oxamic acids is particularly useful as it circumvents the problem of regioselectivity encountered for instance during the $\mathrm{C}-\mathrm{H}$ abstraction in formamides $\left(\mathrm{R}_{2} \mathrm{~N}(\mathrm{C}=\mathrm{O}) \mathrm{H}\right)$, which occurs concurrently at $\mathrm{CHO}$ and to nitrogen, leading to a mixture of products. ${ }^{4}$ Oxidative decarboxylation of oxamic acids may be carried out in the presence of $\mathrm{Ag}(\mathrm{I})$ and $\mathrm{Cu}(\mathrm{II})$ salts, with stoichiometric amount of $\mathrm{K}_{2} \mathrm{~S}_{2} \mathrm{O}_{8}$ as an oxidant in a biphasic medium, as originally proposed by Minisci and co-workers. ${ }^{5}$ These conditions however suffer from the presence of large amount of metal catalysts, and water was shown to be detrimental to the process efficiency, as observed for instance during the preparation of isocyanates. We recently showed that the oxidative decarboxylation of oxamic acid could also be performed conveniently under metal-free conditions in an organic solvent, using an organo-photocatalyst under visible-light irradiation, leading to the corresponding isocyanates in good yields. ${ }^{12}$ When the reaction was carried out in the presence of alcohols, the corresponding urethanes were isolated in excellent yields in a one-pot process. Our mechanistic studies unambiguously showed that a carbamoyl radical was generated under these conditions, which was trapped by unsaturated substrates. We thus report here an extension of this work, with the visible-light mediated addition of oxamic acids onto heteroaromatic bases using a visible-light photoredox catalysis ${ }^{13}$ and an hypervalent iodine reagent as an oxidant (Figure 1). This metal-free procedure enables the amidation of heteroarenes in generally good yields under mild conditions. The method was extended to the carbamoylation of heterocycles using ? ?-aminoacid-derived oxamic acids, which occurred without racemization.

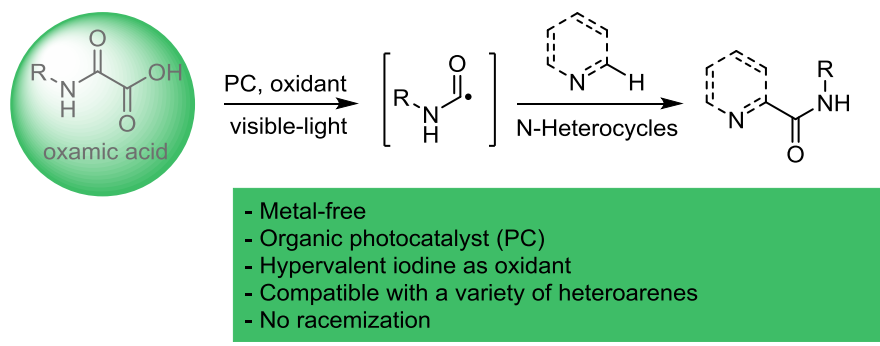

Figure 1 Visible-light mediated amidation of $\mathrm{N}$-heterocycles

Reaction conditions were first optimized, as summarized in Table 1, to access carboxamide 3a from oxamic acid $\mathbf{2 a}$ and lepidine 1a as a model heteroaromatic base (Table 1). Photocatalyst $4 C Z I P N^{14}$ was first tested considering its efficiency in our previous study. Blue LEDs were also selected regarding the maximum UV-vis absorption of 4CzIPN. Preliminary results using hypervalent iodine oxidants such as $\mathrm{PhI}(\mathrm{OAC})_{2}$ (PIDA), PhI(TFA) ${ }_{2}$ (PIFA) and $\mathrm{BI}-\mathrm{OH}$ afforded 3 a in good yields (entries 1-3). However, changing these oxidants for $\mathrm{BI}-\mathrm{OAC}^{15}$ remarkably improved the yield, due to the presence of a better leaving group (OAC) at the iodine center (entry 4). ${ }^{12}$ Eosin-Y and rose Bengal were also tested as photocatalysts, but led only to traces of 3a (entries 6-7), while an acridinium salt ${ }^{16}$ provided $70 \%$ conversion (entry 5). $1.0 \mathrm{~mol} \%$ of $4 \mathrm{CzIPN}, 0.75 \mathrm{mmol}$ of $\mathrm{BI}-\mathrm{OAc}$ in $\mathrm{CH}_{2} \mathrm{Cl}_{2}$ for $12 \mathrm{~h}$ were thus selected as optimal conditions (entry 4). Solvents were also varied, indicating that $\mathrm{CH}_{2} \mathrm{Cl}_{2}$ and DCE were superior (entries 4 and 8), while THF, MeCN, DMF and DMSO led to lower yields (entries 9-12). Finally control experiments were carried out, showing that, photocatalyst, oxidant and light were all essential for the process to occur (entries 13-15). 
Table 1 Addition of oxamic acid $\mathbf{2} \mathbf{b}$ to lepidine $\mathbf{1} \mathbf{a}$.

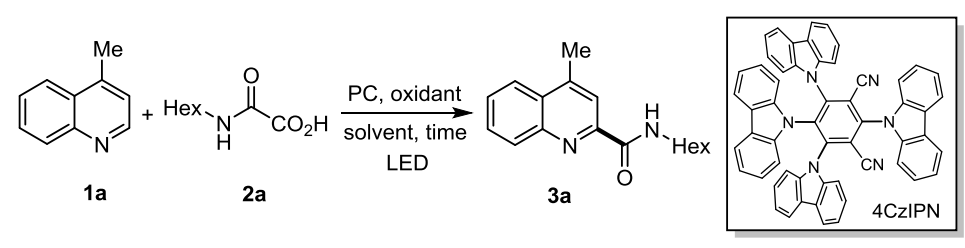

\begin{tabular}{|c|c|c|c|c|c|}
\hline $\begin{array}{l}\text { entr } \\
\mathrm{y}\end{array}$ & PC & oxidant & solvent & $\begin{array}{l}\text { Time } \\
\text { (h) }\end{array}$ & $\begin{array}{l}\text { Yield } \\
(\%) \\
\end{array}$ \\
\hline 1 & 4CzIPN & $\mathrm{Phl}(\mathrm{OAc})_{2}$ & $\mathrm{CH}_{2} \mathrm{Cl}_{2}$ & 12 & 76 \\
\hline 2 & 4CZIPN & $\mathrm{Phl}(\mathrm{TFA})_{2}$ & $\mathrm{CH}_{2} \mathrm{Cl}_{2}$ & 12 & 65 \\
\hline 3 & 4CzIPN & $\mathrm{Bl}-\mathrm{OH}$ & $\mathrm{CH}_{2} \mathrm{Cl}_{2}$ & 12 & 69 \\
\hline 4 & 4CZIPN & $\mathrm{BI}-\mathrm{OAC}$ & $\mathrm{CH}_{2} \mathrm{Cl}_{2}$ & 12 & 95 \\
\hline 5 & AcrMes $^{+} \mathrm{ClO}_{4}^{-}$ & $\mathrm{BI}-\mathrm{OAC}$ & $\mathrm{CH}_{2} \mathrm{Cl}_{2}$ & 12 & 70 \\
\hline 6 & Eosin $Y$ & $\mathrm{BI}-\mathrm{OAC}$ & $\mathrm{CH}_{2} \mathrm{Cl}_{2}$ & 15 & Trace \\
\hline 7 & Rose Bengal & $\mathrm{BI}-\mathrm{OAC}$ & $\mathrm{CH}_{2} \mathrm{Cl}_{2}$ & 12 & NA \\
\hline 8 & 4CZIPN & $\mathrm{BI}-\mathrm{OAC}$ & DCE & 12 & 85 \\
\hline 9 & 4CZIPN & $\mathrm{BI}-\mathrm{OAC}$ & THF & 12 & 33 \\
\hline 10 & 4CZIPN & $\mathrm{BI}-\mathrm{OAC}$ & $\mathrm{MeCN}$ & 12 & 58 \\
\hline 11 & 4CZIPN & $\mathrm{BI}-\mathrm{OAC}$ & DMF & 12 & 51 \\
\hline 12 & 4CzIPN & $\mathrm{BI}-\mathrm{OAC}$ & DMSO & 12 & NA \\
\hline 13 & - & $\mathrm{BI}-\mathrm{OAC}$ & $\mathrm{CH}_{2} \mathrm{Cl}_{2}$ & 12 & NA \\
\hline 14 & 4CZIPN & - & $\mathrm{CH}_{2} \mathrm{Cl}_{2}$ & 12 & NA \\
\hline 15 & 4CZIPN & $\mathrm{BI}-\mathrm{OAC}$ & $\mathrm{CH}_{2} \mathrm{Cl}_{2}$ & 12 & $N A^{d}$ \\
\hline
\end{tabular}

${ }^{a}$ Unless otherwise mentioned, all reactions were performed with 1a (1.0 eq.), 2 b (2.0 eq.), PC (1.0 mol\%) and oxidant (1.5 eq.) in the indicated solvent $(0.2 \mathrm{M})$, in a sealed tube. ${ }^{b}$ Yields of 3 a determined by ${ }^{1} \mathrm{H}$ NMR with $1,3,5$ - trimethylbenzene as an external standard ${ }^{d}$ Isolated yields of $3 \mathbf{a}^{\mathrm{e}}{ }^{\mathrm{e}}$ Absence of blue LED.

With these results, in hands, the substrate scope was extended varying the nature of oxamic acids $\mathbf{2}$ in the presence of Lepidine 1a (Scheme 1). The mild reaction conditions allowed the formation of various amides 3a-n in generally good yields. For oxamic acids bearing sterically hindered substituents, amides where isolated in somewhat lower yields (e.g. 3e). 3m-n, having benzylic substituents sensitive to oxidations were also obtained in high yields.

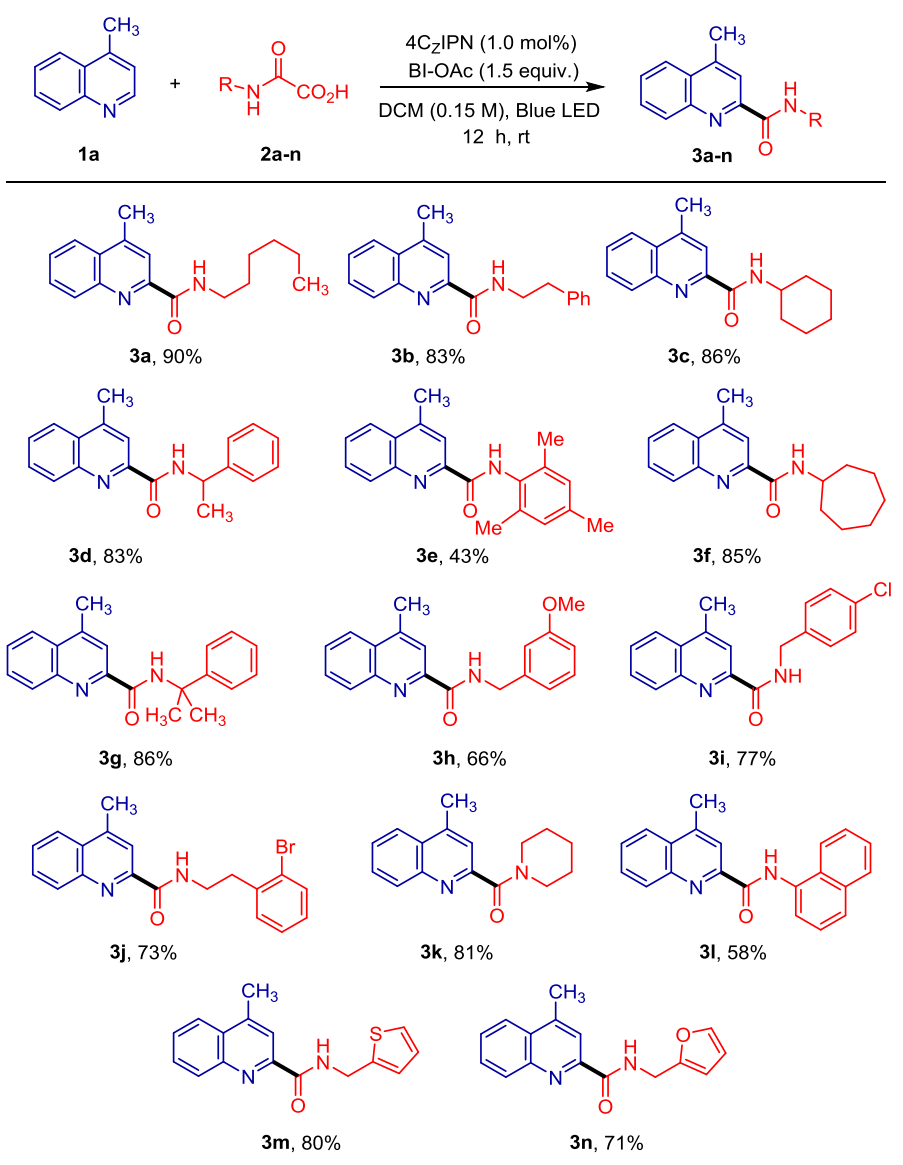

Scheme 1 Oxidative decarboxylation of oxamic acids in the presence of lepidine 1a. Oxamic acid scope. 
Other heteroaromatic compounds were submitted to the optimal reaction conditions above, showing that the method is general, the addition occurring regioselectively ? to the nitrogen (Scheme 2). ${ }^{17}$ Interestingly, in cases where two regioisomers may be formed as in $\mathbf{3 q}, \mathbf{3 r}$ and $\mathbf{3 s}$, only one was observed. Benzimidazole and benzothiazole were found to be competent substrates for the carbamoyl addition, albeit lower yields were observed (e.g. 3x-y). A similar reactivity was observed for 4phenylpyridine, which led to amide 3t in moderate yield. In these cases, the absence of extended aromatic systems probably explain the lower reactivity, the radical intermediate formed upon addition of the carbamoyl radical being less stabilized (vide infra). This may also explain the failure of the addition with several other heteroarenes, including 4-iPr-pyridine, 4-DMAP, indole, furane, (+)-cinchonine, caffeine or pyrrole (see ESI). Considering that carbamoyl radicals are nucleophilic in nature, their addition was also attempted on electron-poor arenes such 1,3-dicyanobenzene or 1,3-( $\left.\mathrm{CF}_{3}\right)_{2}$ benzene, but again not addition was observed under these conditions.

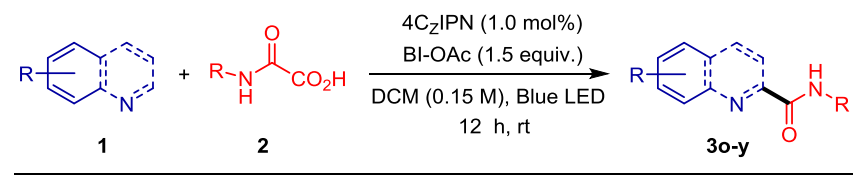<smiles>O=C(NC1CCCCC1)c1ccc2ccccc2n1</smiles>

3o, $80 \%$<smiles>COc1cccc(CNC(=O)c2ncc(Br)c3ccccc23)c1</smiles>

3r, $70 \%$<smiles>CCCCCCNC(=O)c1nc2ccccc2c2ccccc12</smiles>

3u, $93 \%$<smiles>O=C(NC12CC3CC(CC(C3)C1)C2)c1ccc2ccccc2n1</smiles>

3p, $72 \%$<smiles>N#Cc1cccc2c(C(=O)NCc3ccc(F)cc3)nccc12</smiles>

3s, $70 \%$

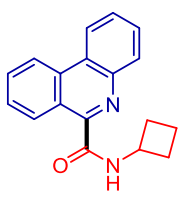

3v, $79 \%$<smiles>CCCCCNC(=O)c1nccc2ccccc12</smiles>

3q, $77 \%$<smiles>CC(NC(=O)c1cc(-c2ccccc2)ccn1)c1ccccc1</smiles>

3t, $57 \%$

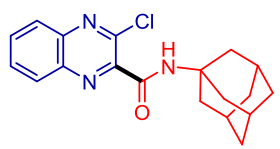

3w, $71 \%$
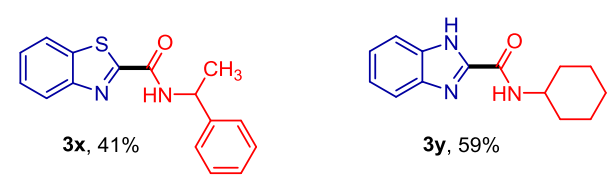

3y, $59 \%$

Scheme 2 Oxidative decarboxylation of oxamic acids in the presence of heteroarenes 1a. heteroarenes scope.

Interestingly, double addition was observed between phthalazine $\mathbf{4}$ as a heteroaromatic base and oxamic acid $\mathbf{2 i}$, affording bis-amide $\mathbf{5}$ in excellent yield (Scheme 3). We were unable to detect the mono-addition product, when using only one equivalent of $\mathbf{2} \mathbf{i}$, suggesting that the mono-amide was much more reactive than $\mathbf{4}$, the first amidation increasing the electron-deficiency of the heteorarene, thus accelerating the second addition. ${ }^{17 c}$ In parallel, bis-amide $\mathbf{7}$ was prepared in moderate yield by coupling two equivalents of lepidine $\mathbf{1 a}$ with bis-oxamic acid 6.

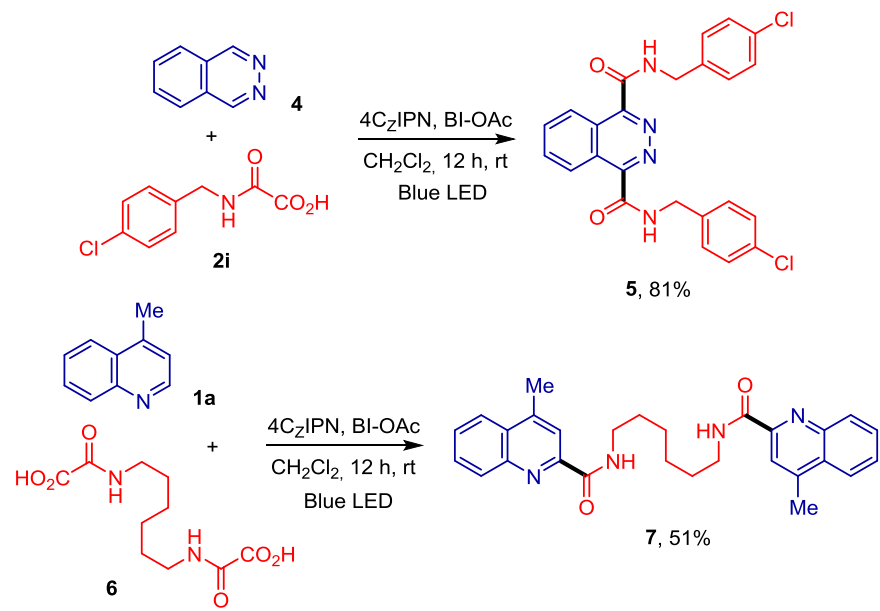

${ }^{a}$ The reaction was carried out with heteroaromatic bases 4 , oxamic acid $\mathbf{2 i}$, PC (1 mol\%) and oxidant (1.5 eq.) in DCE $(0.15 \mathrm{M})$ in a sealed tube. ${ }^{b}$ The reaction was carried out with lepidine 1a, oxamic acid 6, PC (1 mol\%) and oxidant (1.5 eq.) in DCE (0.15 M) in a sealed tube.

Scheme 3 Double oxidative decarboxylation of oxamic acids in the presence of heteroarenes. 
Finally, oxamic acids 8a-b were prepared from the corresponding (L)-amino acids, through an efficient two-steps procedure, involving the treatment of the amine-free amino-ester with $\mathrm{ClCOCO}$-Bu, followed by the removal of the $t$-Bu substituent using TFA (ESI). ${ }^{11} \mathbf{8 a - b}$ were then submitted to the photocatalyzed oxidative decarboxylation in the presence of several heterocycles 1 , leading to the corresponding chiral amides 9a-f in excellent yields (Scheme 4). The reaction was also carried out with rac-8a, and the HPLC signatures of rac-9a and homochiral 9a compared (ESI), to show unambiguously that no racemization occurred during the oxidative process. It is also worth noticing that treatment of $9 \mathrm{a}$ with Lewis acids such as Eu(hfc) ${ }_{3}$ or strong bases $\left(\mathrm{Cs}_{2} \mathrm{CO}_{3}\right)$ led to 9 a with unchanged optical rotation, emphasizing on the high configurational stability of these chiral amides.

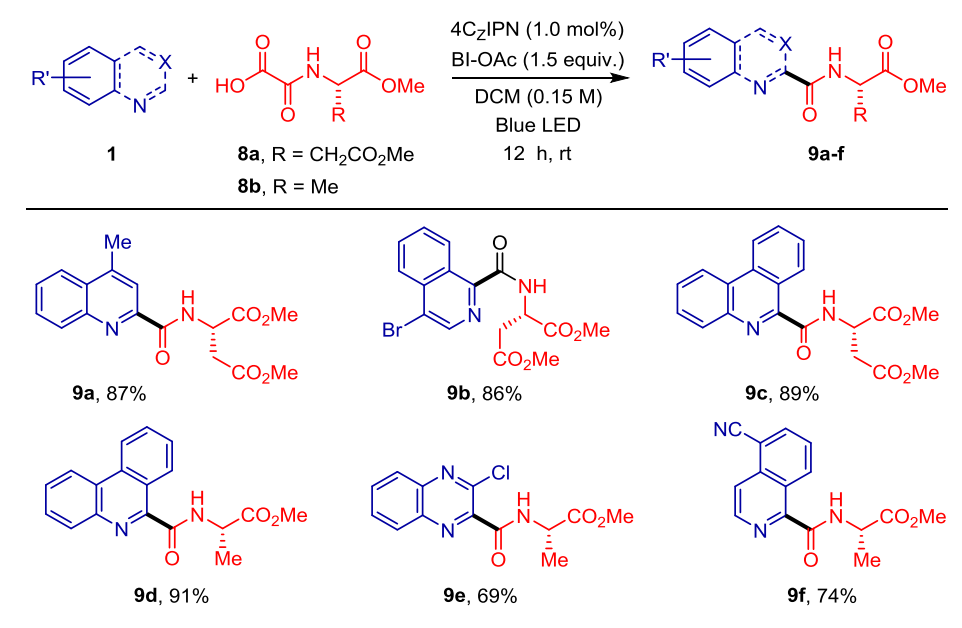

Scheme 4 Oxidative decarboxylation of amino-acids derived oxamic acids.

A tentative mechanism for the carbamoylation of heteroarenes under photoredox conditions is finally proposed, based on our previous trapping experiments (Figure 2). ${ }^{12}$ These studies showed that the key carbamoyl radical III likely results from the formation of a radical-anion II, itself issued from the hypoiodite species I, formed in situ through the coupling between the oxamic acid and BIOAc. ${ }^{18}$ The quenching of the photocatalyst in its excited state by hypoiodite I, would form II, while returning the photocatalyst in its semi-oxidized form $\left(\mathrm{PC}^{+}\right)$. Cleavage of the weak O-I bond in II would then lead to the corresponding amidocarboxyl radical (not shown), which decarboxylation would generate III and $o$-iodobenzoic acid. Radical addition of the carbamoyl radical III onto the heteroaromatic base would form intermediate IV, the oxidation of which, by the radical-cation $\mathrm{PC}^{+}$, generating cationic species V. Deprotonation of the latter and rearomatization would finally give the corresponding amide. ${ }^{17 a, c}$ An alternative mechanism may also be proposed, considering the protonation of the heteroaromatic base under the reaction conditions ( $\mathrm{ACOH}$ is formed), as suggested by Minisci in his seminal studies on the addition of related formamide $\left(\mathrm{HC}(=\mathrm{O}) \mathrm{NH}_{2}\right)$ onto hereoarenes. ${ }^{4,17 a}$ Such a protonation would activate the heteroarene toward the addition of the electron-rich carbamoyl radical to form N-protonated-IV. The ensuing loss of the ?-C-H proton would produce a rather stable allylic captodative radical species, which oxidation (by $\mathrm{PC}^{+}$) would give the final protonated amide. This mechanism cannot be formally ruled out at this stage, although our conditions are much less acidic than those in Minisci's work $\left(\mathrm{H}_{2} \mathrm{SO}_{4}\right)$.

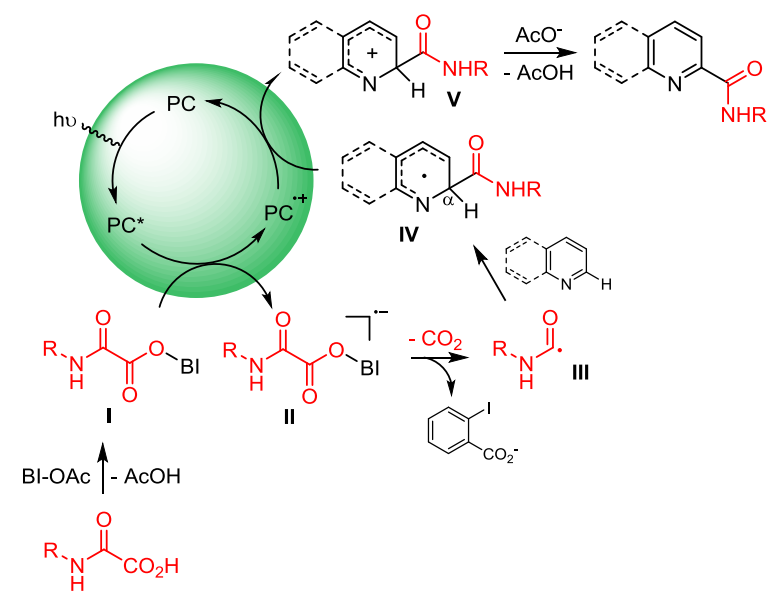

Figure 2 Mechanism of the photocatalyzed decarboxylative amidation of oxamic acids.

In summary, we reported the addition, onto heteroaromatic bases, of carbamoyl radical species generated through a "metalfree" photocatalyzed oxidative decarboxylation of oxamic acids. This strategy allows a straightforward and environmentally benign carbamoylation of a variety of $\mathrm{N}$-heterocycles. The methodology uses readily available starting material as well as standard photocatalyst and organic oxidant sources. Reaction conditions are mild, offering an access to heteroaryl amides derived from amino-acids without racemization. 


\section{Notes and references}

1 Chatgilialoglu, C.; Crich, D.; Komatsu, M.; Ryu, I. Chem.Rev. 1999, 99, 1991.

2 (a) L. Friedman and H. Shechter, Tetrahedron Lett., 1961, 2, 238; (b) D. Elad and J. Rokach, J. Org. Chem., 1964, 29, 1855; (c) R. Dowbenko, Tetrahedron, 1964, 20, 1843; (d) J. Rokach and D. Elad, J. Org. Chem., 1966, 31, 4210; (e) W.-P. Mai, G.-C. Sun, J.-T. Wang, G. Song, P. Mao, L.-R. Yang, J.-W. Yuan, Y.-M. Xiao and L.-B. Qu, J. Org. Chem., 2014, 79, 8094; (f) Q. Jiang, J. Jia, B. Xu, A. Zhao and C.-C. Guo, J. Org. Chem., 2015, 80, 3586; (g) S. Fujiwara, Y. Shimizu, T. Shin-ike and N. Kambe, Org. Lett., 2001, 3, 2085; (h) H. Wang, L.-N. Guo, S. Wang, X.-H. Duan, Org. Lett., 2001, 17, 3054; (i) S. B. Herzon, A. G. Myers, J. Am. Chem. Soc., 2005, 127, 5342; (i) L. V. Jackson, J. C. Walton, Chem. Commun. 2000, 2327; (j) A. F. Bella, L. V. Jackson, J. C. Walton, Org. Biomol. Chem., 2004, 2, 421.

3 (a) M. Yuan, L. Chen, J. Wang, S. Chen, K. Wang, Y. Xue, G. Yao, Z. Luo, Y. Zhang, Org. Lett., 2015, 17, 346; (b) W. F. Petersen, R. J. K. Taylor, and J. R. Donald, Org. Biomol. Chem., 2017, 15, 5831.

4 (a) F. Minisci, A. Citterio, E. Vismara and C. Giordano, Tetrahedron, 1985, 41, 4157; (b) F. Minisci, F. Recupero, C. Punta, C. Gambarotti, F. Antonietti, F. Fontana, and F. Gian, Chem. Commun. 2002, 2496; (c) J. Joseph, A. P. Antonchick, Topics Heterocycl. Chem., 2018, 54, 93.

5 (a) F. Minisci, F. Coppa and F. Fontana, J. Chem. Soc., Chem. Commun., 1994, 679; (b) F. Minisci, F. Fontana, F. Coppa and Y. M. Yan, J. Org. Chem., 1995, 60, 5430.

6 (a) D. Ravelli, S. Montanaro, M. Zema, M. Fagnoni, and A. Albini, Adv. Synth. Catal., 2011, 353, 3295; (b) G. Bencivenni, T. Lanza, R. Leardini, M. Minozzi, D. Nanni, P. Spagnolo and P. Zanardi, J. Org. Chem., 2008, 73, 4721; (c) A. G. M. Barrett, H. Kwonband and E. M. Wallace, J. Chem. Soc., Chem. Commun., 1993, 1760; (d) V. G. Correia, J. C. Abreu, C. A. E. Barata, L. H. Andrade, Org. Lett., 2017, 19, 1060; (e) M. B. Zhou, R.-J. Song, X.-H. Ouyang, Y. Liu, W.-T. Wei, G.-B. Deng, and J.-H. Li, Chem. Sci., 2013, 4, 2690; (f) M. Li, C. Wang, P. Fang, and H. Ge, Chem. Commun., 2011, 47, 6587.

7 (a) A. Millan-Ortiz, G. Lopez-Valdez, F. Cortez-Guzman, L. D. Miranda, Chem. Commun., 2015, 51, 8345; (b) M. Betou, L. Male, J. W. Steed, R. S. Grainger, Chem. Eur. J., 2014, 20, 6505.

8 M. Sakamoto, M. Takahashi, T. Fujita, T. Nishio, I. lida, and S.Watanabe, J. Org. Chem. 1995, 60, 4683.

9 G. B. Gill, G. Pattenden and S. J. Reynolds, J. Chem. Soc., Perkin Trans. 1, 1994, 369.

10 (a) L. N. Guo, H. Wang, X.-H. Duan, Org. Biomol. Chem., 2016, 14, 7380; (b) W. F. Petersen, R. J. K. Taylor, J. R. Donald, Org. Lett., 2017, 19, 874; (c) Q.-F. Bai, C. Jin, J.-Y. He, G. Feng, Org. Lett., 2018, $20,2172$.

11 (a) Y. Seki, K. Tanabe, D. Sasaki, Y. Sohma, K. Oisaki, M. Kanai, Angew Chem. Int. Ed. 2004, 53, 6501; (b) J. Mecinovic, C. Loenarz, R. Chowdhury, C. J. Schofield, Bioorg. Med. Chem. Lett., 2009, 19, 6192.

12 G. G. Pawar, F. Robert, E. Grau, H. Cramail, and Y. Landais, Chem. Commun., 2018, 54, 9337.

13 For selected reviews on visible-light photoredox catalysis, see: (a) C. K. Prier, D. A. Rankic and D. W. C. MacMillan, Chem. Rev. 2013, 113, 5322; (b) J. M. R. Narayanam and C. R. J. Stephenson, Chem. Soc. Rev., 2011, 40, 102; (c) N. A. Romero and D. A. Nicewicz, Chem. Rev., 2016, 116, 1007; (d) L. Marzo, S. K. Pagire, O. Reiser and B. König, Angew. Chem., Int. Ed., 2018, $57,10034$.

14 H. Uoyama, K. Goushi, K. Shizu, H. Nomura, C. Adachi, Nature, 2012, 492, 234.

15 Y. Li, D. P. Hari, M. V. Vita, and J. Waser, Angew. Chem. Int. Ed. 2016, 55, 44.

16 S. S. Fukuzumi, H. Kotani, K. Ohkubo, S. Ogo, N. V. Tkachenko, and H. Lemmetyinen, J. Am. Chem. Soc., 2004, 126, 1600.

17 For a discussion on the regioselectivity of radical additions to heteroarenes, see: (a) F. Minisci, F. Fontana, E. Vismara, J. Heterocycl. Chem. 1990, 27, 79; (b) F. O’Hara, D.G. Blackmond, P.S. Baran, J. Am. Chem. Soc. 2013, 135, 12122; (c) J. Tauber, D. Imbri, T. Opatz, Molecules, 2014, 19, 16190.

18 (a) H. Tan, H. Li, W. Ji, L. Wang, Angew. Chem. Int. Ed., 2015, 54, 8374; (b) H. Huang, G. Zhang, L. Gong, S. Zhang, Y. Chen, J. Am. Chem. Soc., 2014, 136, 2280; (c) H. Huang, K. Jia, Y. Chen, Angew. Chem. Int. Ed., 2015, 54, 1881; (d) H. Huang, K. Jia, Y. Chen, ACS Catal., 2016, 6, 4983; (e) J. Genovino, Y. Lian, Y. Zhang, T. O. Hope, A. Juneau, Y. Gagné, G. Ingle, M. Frenette, Org. Lett., 2018, 20, 3229. 